\title{
PRÁTICAS DE LEITURA EM SALA DE AULA: UMA SEQUÊNCIA DIDÁTICA PARA O LETRAMENTO LITERÁRIO ${ }^{1}$
}

\author{
Isaías Francisco de Carvalbo ${ }^{* *}$ \\ João Valci dos Santos Novaes*** \\ Rosilma Silva Rodrigues ${ }^{* * * *}$
}

\begin{abstract}
RESUMO: O trabalho discute questões referentes à leitura em sala de aula, enfatizando-a como processo fundamental para o desenvolvimento da expressão, comunicação e interação social dos educandos. Compreendendo a prática de leitura na escola como uma atividade que demanda planejamento e elaboração de objetivos, tecemos argumentos em favor do uso das estratégias para favorecer a compreensão leitora e interpretativa, em situações contextualizadas. Para tanto, sugerimos uma proposta de ensino elaborada a partir do modelo de sequência didática delineada por Dolz, Noverraz e Schneuwly (2004). Utilizamos a crônica "O lixo”, de Luís Fernando Veríssimo, como objeto literário. Para fundamentar esta proposta, nos respaldamos, entre outros, nos estudos de Oliveira (2010), Solé (1998), Cosson (2014) e Colomer e Camps (2002), os quais apresentam pertinentes contribuições sobre práticas de leitura e compreensão leitora no espaço escolar, assim como reflexões acerca da formação do leitor de textos literários.
\end{abstract}

PALAVRAS-CHAVE: Estratégias de leitura; Leitura literária; Sequência didática.

\footnotetext{
${ }^{1}$ Trabalho elaborado a partir da consolidação dos resultados de pesquisa apresentados (com resumo publicado) no VI SIELP - Simpósio Internacional de Ensino de Língua Portuguesa, na Universidade Federal de Uberlândia, ocorrido nos dias 19, 20 e 21 de outubro de 2016.

** Doutor em Teorias e Crítica da Literatura e da Cultura. Professor de Literaturas Anglófonas e de Língua Inglesa vinculado aos programas de Mestrado em Letras: Linguagens e Representações e Mestrado Profissional em Letras (Profletras) da Universidade Estadual de Santa Cruz - UESC. E-mail: isaiasfcarvalho@gmail.com

${ }^{* * *}$ Mestre em Letras pela Universidade Estadual de Santa Cruz - UESC. E-mail: joaovalci@hotmail.com

${ }^{* * * *}$ Mestra em Letras pela Universidade Estadual de Santa Cruz - UESC. Email: rosilmasr2@gmail.com
} 


\section{Introdução}

A leitura literária cumpre um papel fundamental no processo de ensino e, consequentemente, na formação do leitor. Além de permitir o acesso do aluno ao universo da cultura letrada, a experienciação do texto literário permite que esse aluno aguce o refinamento estético e imaginativo, como também colabora diretamente para o desenvolvimento do pensamento crítico e cognitivo.

Consideramos importante lembrar que o texto literário compreende, em sua estrutura composicional, um conjunto de especificidades - estéticas e estilísticas - que proporcionam a fruição da leitura a partir de uma ótica muito particular. Sem mencionar que, do ponto de vista temático, a abordagem literária pode favorecer a reflexão sobre aspectos sociais, históricos e culturais em tempos e espaços diversos, em que a/o aluna/o-leitor/a tem uma oportunidade singular de ampliar sua compreensão do mundo, do outro e de si mesma/o.

Nessa perspectiva, Cosson (2014, p. 120) esclarece que "[...] ser leitor de literatura na escola é também posicionar-se criticamente diante do texto literário, identificando e questionando protocolos de leitura, afirmando ou retificando valores culturais, elaborando e expandindo sentidos". Portanto, é entendemos ser preciso (re)significar o papel exercido pela leitura literária comumente praticada em sala de aula, tendo em vista tanto a formação intelectual e crítica, quanto o refinamento da sensibilidade estética dessa/e leitor/a em formação. Corroborando nessa mesma linha, Rangel enfatiza que o

[...] ensino de língua portuguesa tem dado insuficiente atenção ao papel da leitura literária no desenvolvimento dessas tão visadas proficiências. E que, por outro lado, temos refletido pouco sobre aspectos da leitura que não estão diretamente relacionados à proficiência, como a própria constituição do sujeito leitor, no processo de ensino aprendizagem. (RANGEL, 2014, p. 146).

Por isso, faz-se necessário a sistematização de práticas leitoras em nossas escolas para que a/o aluna/o possa vivenciar uma experiência significativa com a leitura literária. Nesse processo de desenvolvimento de estratégias de planejamento, concordamos com 
Zilberman (2008, p. 18), quando destaca que o “[...] texto literário favorece a formação do indivíduo, cabendo, pois, expô-lo como matéria-prima literária, requisito indispensável no aprimoramento intelectual e ético do aluno leitor em formação”. Cosson (2014, p. 120), por seu turno, ressalta que esse aprendizado crítico da leitura literária “[...] não se faz sem o encontro pessoal com o texto enquanto princípio de toda experiência estética, ou seja, sem o letramento literário.”

Assim sendo, buscamos fazer com que a leitura do texto literário seja uma atividade previamente pensada pela/o professor/a, mediador/a de possibilidades e intervenções, por meio da qual possa direcionar o aluno para a fruição estética e estilística presentes na tessitura do próprio texto literário selecionado. Portanto, colocamos a leitura literária para além de urgências imediatistas, mas numa dimensão tal de alcance que venha contribuir para a ampliação de horizonte de mundo da/o aluna/o sujeita/o leitor/a.

\section{Leitura em sala de aula: aspectos importantes para a compreensão leitora}

Ler pode ser considerado um ato fundamental para todos nós. Por meio da leitura, podemos ampliar nossos conhecimentos e desenvolver nossas habilidades de expressão, comunicação e interação no meio em que vivemos. Estudos sobre a leitura têm admitido que aprendemos a ler fluentemente quando interagimos em nossas relações na sociedade, nas trocas de experiências e aprendizagens promovidas pela escola. De acordo os Parâmetros Curriculares Nacionais (PCN),

A leitura é o processo no qual o leitor realiza um trabalho de compreensão e interpretação do texto, a partir de seus objetivos, de seu conhecimento sobre o assunto, sobre o autor, de tudo o que sabe sobre a linguagem etc. Não se trata de extrair informação, decodificando letra por letra, palavra por palavra. Trata-se de uma atividade que implica estratégias de seleção, antecipação, inferência e verificação, sem as quais não é possível proficiência. (BRASIL, 1998, p. 69).

Nessa perspectiva, a leitura é importante no processo ensino-aprendizagem, pois é ponto de partida para que a/o aluna/o se torne um/a leitor/a proficiente em todas as 
disciplinas. Tendo em vista as funções que desempenha dentro do ensino de línguas, Antunes (2009) sugere que a leitura não deve estar ligada apenas ao ato de ensinar a decifrar sinais gráficos ou na inserção da/o aluna/o no mundo da cultura letrada.

De acordo com o autor, a prática de leitura não deve ser função apenas da/o professor/a de português, uma vez que "Todo professor, de qualquer disciplina, é um leitor e, para sua atividade de ensino, depende, necessariamente, do convívio com textos dos mais diversos." (ANTUNES, 2009, p. 187). Assim, à/ao professor/a de qualquer disciplina compete, também, a responsabilidade de desenvolver um trabalho pedagógico voltado para a ampliação das diferentes competências proporcionadas pela atividade da leitura.

Tendo em vista que o processo de leitura exige da/o leitor/a determinados conhecimentos prévios, é fundamental também aos usuários da língua a aquisição de aprendizagens ligadas aos conhecimentos linguísticos, aos conhecimentos enciclopédicos ou de mundo e aos conhecimentos textuais. Oliveira (2010, p. 60) afirma que esses três tipos de conhecimentos são essenciais para a efetivação da leitura. O autor aponta que “[...] a falta do conhecimento linguístico é a causa mais óbvia da impossibilidade de uma pessoa analfabeta ler um texto". No entanto, o autor enfatiza que "[...] mesmo pessoas escolarizadas podem se deparar com textos que lhes causem problemas de leitura devido à falta de conhecimentos lexicais específicos."

Nesse sentido, sabendo que a aprendizagem da leitura, de modo proficiente, ocorre através da interação entre os diversos conhecimentos, devemos considerar que as dificuldades apresentadas por nossas/os alunas/os, enquanto leitoras/es, possivelmente estejam vinculadas à falta de interação entre os conhecimentos linguísticos, lexicais e enciclopédicos, uma vez que o ato de ler exige algumas ações necessários para a aquisição das informações implícitas no texto.

Dentre os procedimentos necessários para compreensão de um texto, pesquisadores e teóricos apontam três modelos fundamentais nesse processo: o bottom-up, o top-down e o interativo. De acordo com Oliveira (2010), o processamento ascendente (ou modelo bot- 
tom-up, do inglês) corresponde ao momento em que o leitor busca os conhecimentos linguísticos para decodificar as informações do texto, que constitui o elemento primordial no ato de ler. No processamento descendente (ou top-down, do inglês), a/o leitor/a é o elemento principal, pois lança mão de seus conhecimentos enciclopédicos e textuais para chegar à compreensão de um texto, partindo dos aspectos mais globais para as unidades menores.

O terceiro modelo, o interativo, corresponde a uma junção dos modelos ascendente e descendente. Nesse caso, a/o leitor/a orienta a leitura integrando os conhecimentos semânticos, sintáticos e fonéticos, a fim de alcançar uma interpretação pessoal do texto. A proposta desse modelo parte da noção de uma "[...] aproximação da leitura mediante a combinação de análise e síntese, que inclui o ensino explícito da decifração em contextos significativos, [sendo] preciso continuar ensinando estratégias de leitura mesmo depois que o estudante aprendeu a ler.” (SOLÉ, 2003, p. 25).

Por isso, promover estratégias de leitura no espaço escolar é muito importante no processo de interpretação e compreensão dos textos escritos. Solé (1998) afirma que todo trabalho com leitura em sala de aula exige um planejamento que contemple diversos aspectos, tais como a motivação, a definição de objetivos claros e a elaboração de estratégias. Para a autora, ao utilizar uma estratégia didática a/o professor/a estará oferecendo às/aos alunos “[...] recursos necessários para aprender a aprender.” (SOLÉ, 1998, p. 72), uma vez que nela são abordados aspectos essenciais na otimização da compreensão leitora, bem como no desenvolvimento de possíveis estratégias que envolvem esse processo.

Segundo Solé (1998), as estratégias de leitura são procedimentos. Logo, precisam ser ensinadas, não como técnicas precisas ou receitas infalíveis, mas como recursos fundamentais que visem uma melhor compreensão leitora. Para isso, é preciso que a/o professor/a elabore objetivos claros e faça o planejamento das ações a serem desenvolvidas. A autora propõe estratégias que enfatizam momentos essenciais para que ocorra a efetivação da leitura significativa. Segundo ela, antes de iniciar a leitura de um texto, é necessário que ocorra uma motivação. Nesse momento, o professor irá formular perguntas sobre o texto 
de modo a mobilizar os conhecimentos prévios dos alunos, com especial atenção para aspectos importantes da leitura, tais como o assunto abordado, o gênero textual em estudo e o autor do texto. Esse momento é essencial para despertar o interesse e a curiosidade dos alunos para a leitura do texto.

Solé destaca ainda que "[...] o leitor ativo é aquele que processa, critica, contrasta e avalia a informação que tem diante de si, que a desfruta ou a rechaça, que dá sentido e significação ao que lê" (SOLÉ, 2003, p. 21). Assim, durante o processo da leitura, a autora propõe que a/o professor/a faça uso da leitura compartilhada, na qual a/o aluna/o tem papel ativo na compreensão leitora, uma vez que lidera as discussões ao participar ativamente, fazendo previsões sobre o texto, formulando perguntas que podem ser respondidas pelos demais alunos e esclarecendo suas dúvidas.

Após a leitura do texto, a autora sugere que a/o professor/a aborde aspectos relacionados ao tema do texto, orientando os estudantes a encontrarem a ideia principal, o tema dos parágrafos, assim como identificar ideias repetidas ou agrupadas nos parágrafos. Nesse momento também podem ser discutidas questões sobre o enredo do texto, a linguagem, suas características principais e secundárias, concluindo com a recapitulação e o resumo do texto.

Como percebemos, uma compreensão eficiente da leitura é uma atividade complexa que depende da elaboração de estratégias e dos processos cognitivos, linguísticos e perceptivos para que o sujeito construa os conhecimentos necessários em relação ao texto em estudo. Nesse sentido, os PCN enfatizam que “[...] o leitor competente é capaz de ler as entrelinhas, identificando, a partir do que está escrito, elementos implícitos, estabelecendo relações entre o texto e seus conhecimentos prévios ou entre o texto e outros textos já lidos" (BRASIL, 1998, p.70). A partir dessa perspectiva, a/o professor/a, em seu papel de mediador/a no desenvolvimento da competência leitora das/os alunos, é responsável na tarefa de auxiliar as/os estudantes nesse processo, buscando estratégias de leitura que visem a facilitar a compreensão de um texto. 
Conforme constatamos, as atividades de leitura em sala de aula precisam ser planejadas tendo em vista estratégias que proporcionem à/ao aluna/o uma melhor compreensão leitora. A/O professor desempenha um papel importante nesse processo, visto que lhe cabe "[...] organizar momentos de leitura livre em que também ele próprio leia, criando um circuito de leitura em que se fala sobre o que leu, trocam-se sugestões de leitura, aprendese com a experiência do outro." (BRASIL, 1998, p. 71).

\section{Leituras e leitores: por que utilizar o texto literário em sala de aula?}

Dentre os diversos motivos que se podem elencar para advogar o uso do texto literário no espaço escolar, existe entre as/os especialistas da área um consenso quando se trata da formação do leitor. Nesse sentido, as práticas de leitura devem contribuir para o favorecimento de dois objetivos complementares: um caráter cognitivo, outro social. A propósito, como já apontam as novas orientações da segunda versão revista da Base Nacional Comum Curricular (BNCC) quando destacam como objetivos do campo literário “[...] uma experiência formativa pessoal, que ocorre por meio da apreciação estética, sendo, nesse caso, promovida pelo contato direto com o texto literário; e uma outra formação para o exercício da cidadania.”(BRASIL, 2016, p. 90), que envolve, por exemplo, a compreensão crítica do mundo, da realidade, do outro e de si mesmo diante da vida.

Corroborando nessa mesma concepção, Rangel (2007, p. 129) afirma que a “[...] leitura literária cumpre tanto uma função cognitiva, quanto histórico-cultural. Destacando que, no primeiro caso, o foco são as competências e habilidades implicadas no processo, assim como nas estratégias de abordagem e o processamento do texto. Já no segundo caso, a preocupação é com o resgate dos significados culturais historicamente atribuídos ao contexto de produção e recepção do texto.

Nesse caso, a abordagem do texto literário em sala de aula permite uma experiência singular que perpassa desde a apreciação estética ao conhecimento de diferentes fatores 
histórico-culturais. Essas especificidades da leitura do texto literário não podem ser desconsideradas ou mesmo relegadas a um segundo plano. É preciso, portanto, como ressalta Zilberman (2008, p. 24), que o “[...] exercício da leitura seja o ponto de partida para o acercamento à própria literatura", de maneira que o texto literário seja posto como matériaprima do processo de ensino-aprendizagem.

Enquanto prática social, Rezende (2013, p. 107) aborda que “[...] a leitura de uma obra literária, sugere, antes de tudo, um movimento de identificação: lemos o que gostamos de ler, [...]". Assim, estamos sempre buscando leituras com as quais nos identificamos, que foram indicadas por alguém ou simplesmente porque se trata de uma obra que despertou nossa curiosidade para leitura. Conforme a autora, lemos também devido aos nossos "[...] interesses, proficiências, ideologias [...]" ou exercemos a leitura unicamente como meio de fruição e prazer.

Assim, nessa perspectiva, a leitura literária pode ser entendida como uma experiência subjetiva, na qual o aluno sujeito leitor traz para a materialidade do texto e da leitura suas vivências, percepções e conhecimento de mundo. Conforme Rangel (2007, p. 129), “[...] ainda que a escola faça da leitura um investimento pedagógico prioritário, a leitura literária, naquilo que tem de próprio e, portanto, de constitutivo dessa experiência subjetiva, fica obscurecida."

Em contrapartida, é possível pensar em práticas de leitura que colaborem também para a formação da/o leitor/a literário. Para tanto, é preciso que o texto ocupe esse espaço privilegiado de construção de sentidos, possibilitando a aquisição de valores éticos e estéticos, em nome dos quais a literatura participa efetivamente da vida social e do imaginário das/os leitoras/es. Sendo assim, podemos dizer, como enfatiza as OCEM (2006, p. 54): “[...] trata-se, prioritariamente, de formar o leitor literário, melhor ainda, letrar literariamente o aluno, fazendo-o apropriar-se daquilo a quem tem direito.”

É na perspectiva do letramento literário que compreendemos a função que a literatura exerce na formação do leitor. Nesse sentido, a leitura literária tem um papel basilar “[...] como prática que permite aos cidadãos exercerem o poder sobre a linguagem e, por 
meio dela, pensar a experiência e compreender alguns dos modos pelos quais o mundo opera.” (SILVA, 1998 apud DIONÍSIO, 2014, p. 72). Portanto, a utilização do texto literário deve ter como finalidade formar leitores capazes de compreender, pela leitura, a diversidade cultural presente nos diferentes aspectos da vida social, política, histórica e cultural ressignificando valores e opiniões críticas acerca de sua própria trajetória de vida. Ainda segundo Dionísio (2014),

[...] ser leitor, nessa perspectiva, vai para além da competência técnica, envolvendo, também o que podemos chamar um nível cultural, isto é, reconhecer e ter consciência de que as práticas de leitura e, mais vastamente, de literacia são sempre mais do que simplesmente uma questão de operar com o sistema linguístico, mas, que nesse caso, opera também outras formas significação. (DIONÍSIO, 2014, p. 75 , grifo nosso).

Nesse sentido, é importante salientar que, tão importante quanto utilizar o texto literário em sala de aula, é saber, previamente, como usá-lo, direcionando-o a partir de práticas de letramento que favoreçam a compreensão das diversas relações que se estabelecem à volta da materialidade constitutiva e estética do texto, com outras funções histórico-culturais que corroboram para a formação de leitor cosmopolita.

\section{Sequências didáticas: uma proposta de ensino com texto literário}

É grande a diversidade de textos que circulam atualmente dentro e fora do contexto escolar. Desse modo, o trabalho com gêneros literários em sala de aula deve propiciar às/aos estudantes a compreensão de suas particularidades, usos, funções e flexibilidades, possibilitando o domínio efetivo da língua, assim como a construção dos sentidos e aquisição de aprendizagens significativas para a/o educanda/o.

Nesse sentido, acreditamos ser possível desenvolver a capacidade leitora das/os estudantes por meio de propostas de ensino que envolvam a aplicação de sequências didáticas (SD) em sala de aula, definidas pelos autores genebrinos, Dolz, Noverraz e Schneuwly (2004), como ferramentas eficazes para atividades de leitura, escrita, audição e fala. 
O objetivo de uma sequência didática, segundo esses autores, é primordialmente possibilitar às/aos alunas/os o acesso a práticas de linguagens diversificadas, oferecendolhes instrumentos eficazes para melhorar as capacidades de leitura, escrita, expressão e comunicação oral, com o intuito de transformar as atividades de leitura em sala de aula em momentos significativos de aprendizagem.

Afirmam ainda que a SD possibilita às/aos estudantes ampliarem os conhecimentos acerca dos gêneros textuais que circulam em seu meio social, oferecendo-lhes melhores condições para expressarem-se através da leitura e da escrita, tanto dentro como fora do ambiente escolar. A estrutura de base da sequência didática apresentada pelos autores genebrinos é constituída pelos seguintes passos: apresentação da situação, produção inicial, módulo I, módulo II, módulo III e produção final, conforme demonstração no esquema na Figura 1.

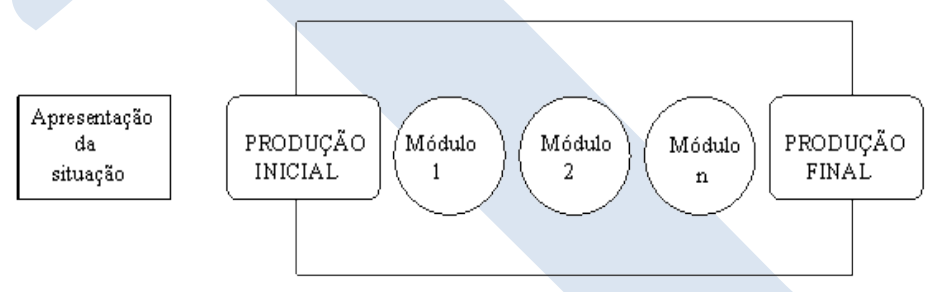

Figura 1 - Esquema da sequência didática (DOLZ et al, 2004, p. 98)

O ponto de partida da SD é a apresentação da situação, na qual o professor expõe às/aos alunas/os o projeto que será trabalhado, qual a temática a ser discutida e o gênero textual escolhido, assim como o destinatário da produção e o suporte de leitura. Na etapa seguinte, intitulada de produção inicial, a/o aluna/o realiza a primeira produção escrita do gênero em estudo, propiciando à/ao professor/a um diagnóstico dos conhecimentos, das capacidades e das dificuldades das/os alunas/os. Esses dados servirão de suporte para a/o 
professor/a planejar as atividades de intervenção que serão desenvolvidas nos módulos I, II e II.

Preparar o conteúdo que será trabalhado ao longo dos módulos da SD é uma tarefa que exige muita responsabilidade por parte da/o professor/a, uma vez que as atividades propostas devem buscar sanar as dificuldades verificadas durante a primeira escrita e preparar as/os alunas/os para a realização da produção final. Assim, durante os módulos, algumas atividades voltadas para aspectos discursivos, linguísticos e textuais, podem ser contempladas na sequência, buscando ampliar o nível de aquisição e aprendizagem dos conhecimentos abordados durantes as aulas.

A última etapa da SD é realização da produção final, vista como o momento em que as/os alunas/os colocam em prática os conhecimentos adquiridos ao longo do processo. Também é a fase em que a/o professor/a confronta a produção inicial com a produção final desenvolvida verificando, através da avaliação somativa, se os objetivos propostos para a SD foram alcançados.

Tendo em vista essas concepções, sugerimos aqui uma proposta de atividade didática para aulas de Língua Portuguesa, elaborada a partir do modelo de sequência didática sugerido por Dolz, Noverraz e Schneuwly (2004), que apresenta uma série de atividades pedagógicas organizadas de maneira ordenada, a partir de um determinado gênero textual.

A proposta de atividade aqui apresentada tem como temática "Responsabilidade e cuidado com o meio ambiente: dever de todos nós", direcionada aos estudantes do oitavo ano do Ensino Fundamental II, tendo como foco o uso do texto literário na sala de aula, especificamente do gênero textual crônica, do qual foi escolhido o texto “O lixo”, de Luís Fernando Veríssimo, como objeto literário basilar. Apresentamos uma diversidade de atividades possíveis de serem desenvolvidas em um período de 12 aulas, divididas em seis encontros, com duas horas-aula.

As atividades propostas objetivam ampliar a competência leitora e escrita das/os estudantes, articulando o domínio dos conhecimentos acerca do gênero crônica aos conhecimentos linguísticos e textuais como elementos fundamentais para aquisição dos sentidos 
do texto. Essas atividades também buscam contribuir, concomitantemente, com a ampliação da leitura literária no ambiente escolar. A seguir, a sistematização da SD.

\section{Sequência didática}

"Responsabilidade e cuidado com o meio ambiente: dever de todos nós!"

\section{Competências:}

- Ampliar a competência leitora;

- Reconhecer as principais características do gênero crônicas;

- Produzir textos do gênero crônica.

\section{Habilidades:}

- Reconhecer a necessidade de preservar o meio ambiente;

- Assimilar novos vocabulários;

- Refletir sobre a crítica contida na crônica;

- Confirmar antecipações e inferências realizadas antes e durante o estudo do gênero crônica.

\section{Conteúdos:}

- Gênero textual crônica;

- Sequência da narrativa;

- Sinais de pontuação;

- Ortografia;

- Uso dos pronomes de tratamento.

\section{Objetivos:}

- Geral:

- Ampliar a competência leitora e interpretativa dos educandos por meio do gênero literário crônica.

- Específico:

- Desenvolver práticas de leitura e escrita;

- Propiciar o contato com outros gêneros textuais que abordam a temática em estudo; 
- Analisar o uso dos sinais de pontuação nos diálogos estabelecidos na crônica;

- Analisar o emprego dos pronomes de tratamento entre as personagens da crônica;

\section{Recursos:}

- Letra de música impressa; data show; vídeo; texto impresso; caderno; lápis; caneta; borracha; aparelho de som; quadro branco, dicionário; cartaz; imagem, foto, celular, tablet.

\section{Descrição das atividades}

\section{$1^{\circ}$ encontro - Apresentação da temática - Para começo de conversa...}

No primeiro encontro, para começo de conversa, será apresentada aos alunos a temática a ser discutida, que trata da "Responsabilidade e cuidado com o meio ambiente: dever de todos nós". Em seguida, será distribuída entre os alunos a letra da música "Mixturação", de Carlinhos Brown, podendo ser apresentada através da audição da letra em aparelho de som, com uso de CD ou pen drive, ou através da exibição um vídeo, encontrado no link < https://www.youtube.com/watch?v=DrL9kkQ2nvM>.

A partir daí ocorrerá, através de questionamentos orais, o levantamento dos conhecimentos prévios dos estudantes acerca da temática:

- Você já conhecia essa música?

- $\quad$ O que sabe sobre Carlinhos Brown? Conhece outras canções dele?

- Sobre o que fala a letra dessa música?

- É possível perceber na música um posicionamento do compositor? Qual seria?

- Quais são os outros gêneros textuais que você conhece que podem abordar o tema meio ambiente?

- Você cuida do meio ambiente? De que forma?

- Existem problemas ambientais em sua cidade? Quais? 
Após essa sondagem inicial, apresentar para os alunos, através de cópia impressa, a crônica “O lixo", de Luís Fernando Veríssimo, disponível em <http://7leitores.blogspot.com.br/2008/07/o-lixo-luis-fernando-verssimo.html>, fazendo um breve comentário sobre o gênero que será estudado, abordando questões como:

- Origem e história das crônicas;

- Acontecimentos que retratam;

- Características, estrutura e finalidade;

- Tipos de crônicas e tons utilizados pelos cronistas.

É importante também abordar sobre o autor do texto, se já ouviram falar, se conhecem alguma obra que ele publicou, assim como sua importância para a literatura brasileira na atualidade.Posteriormente, sugerimos a leitura compartilhada do texto, que poderá ser realizada por duas pessoas (dois estudantes ou pelo professor e um estudante), já que se trata de um diálogo entre as duas personagens da história.Logo após, sugerimos uma breve discussão, na qual os alunos serão provocados com perguntas como:

- Qual o assunto tratado na crônica?

- A crônica traz, implícita ou explicitamente, uma crítica a alguma situação da vida em sociedade? Explique sua resposta.

- Qual relação você estabelece entre esse texto e a letra da música?

- Você considera o tema abordado na crônica um problema? Por quê?

- Em quais veículos de comunicação ela pode ser publicada?

- A que tipo de leitor se destina? 
- O tom da escrita é bem-humorado, poético, irônico reflexivo ou sério? Comente.

\section{$2^{\circ}$ encontro - Produção inicial - Na continuidade da história...}

Para realização da primeira escrita, é necessário que o professor relembre às/aos alunos aspectos ligados aos elementos da narrativa, como, por exemplo, as personagens, o espaço, o tempo, foco narrativo e o enredo. Essa explicação poderá ocorrer por meio da apresentação de slides ou com exibição do vídeo baixado através do link <https://www.youtube.com/watch?v=w8zZ4MbE8GQ>, que faz parte dos materiais pedagógicos da editora FTD e apresenta, por meio do conto "Nas garras do primeiro amor", presente na obra O menino no espelho, de Fernando Sabino, os elementos que fazem parte de uma narrativa.

Para realizar a produção, as/os alunos serão divididas/os em grupos de três ou quatro componentes e receberão uma folha impressa com os parágrafos finais do texto, solicitando que eles deem continuidade à narrativa, construindo um possível diálogo entre a senhora do 610 e o senhor do 612, acrescentando novos elementos e situações à história. É imprescindível que o professor oriente os alunos para que realizem uma releitura da crônica, a fim de colher informações que poderão ajudá-las/os a construir a continuidade da história, tais como o cenário em que as personagens se encontram, a forma de tratamento que utilizam, se o enredo narra um episódio banal do dia a dia, o tipo de linguagem que o autor utiliza e outros.

Ao final da produção, os grupos deverão socializar com a turma o texto que produziu e, na sequência, a/o professor/a pode recolher as produções para analisar os possíveis desvios linguísticos e preparar as atividades que permitirão às/aos estudantes realizar a refacção do texto de maneira mais eficiente. 


\section{$3^{\circ}$ encontro: Módulo I: O que diz a primeira escrita?}

O primeiro módulo é dedicado à análise coletiva da primeira produção. Para isso, será necessário que os grupos montados anteriormente se reúnam, enquanto a/o professor/a distribui aleatoriamente um dos textos produzidos para que cada equipe faça a análise da produção das/os colegas. Nesse momento, os grupos serão orientados a observarem se as produções contemplam aspectos como:

- O tema está coerente com a proposta?

- Há descrições de um fato ou relato de uma situação?

- Os diálogos são coerentes?

- $\quad$ tom da narrativa está adequado à temática?

- Há problemas de pontuação no texto?

- Os pronomes de tratamento foram usados adequadamente?

- Existe um elemento surpresa na história?

- Há passagens que se repetem e podem ser agrupadas? Destaque-as.

Em seguida, a/o professor/a distribui uma ficha de avaliação, solicitando aos grupos que elaborem um pequeno relatório ressaltando os problemas que identificaram, propondo possíveis alterações para aperfeiçoar o texto. As produções, assim como os relatórios, deverão ser recolhidas pela/o professor/a.

Nessa etapa, convém à/ao professor/a também apresentar, em forma de cartaz, os diálogos que aparecem escritos nas produções em que a pontuação não foi empregada de forma adequada. Posteriormente, solicita às/aos alunos que apresentem hipóteses sobre os fatores que provavelmente contribuíram para a ocorrência desses desvios. Tendo em vista as dificuldades das/os alunas/os em empregar os sinais de pontuação de maneira correta, consideramos necessário que a/o professor/a faça uma breve revisão, explicando as funções e emprego dos sinais nos discursos 
diretos, indiretos e indiretos livre, enfatizando os que aparecem com mais frequência nos textos que apresentam diálogos diretos.

\section{$4^{\circ}$ encontro: Módulo II: Os recursos linguísticos e expressivos}

Nesse módulo, sugerimos que a/o professor/a proponha para turma questões que propiciem às/aos alunas/os analisar os recursos discursivos e linguísticos utilizados pelo cronista, para que todos tenham a oportunidade de se expressarem. Seguem algumas questões que podem ser exploradas, de forma oral ou escrita:

- Você gostou da crônica? Justifique sua resposta.

- Que sentimentos ou emoções ela nos desperta?

- A situação mostrada na crônica revela um drama comum a todas as cidades? Justifique.

- Quem são as personagens? Quais características físicas e psicológicas você atribui a elas?

- $\quad$ O autor faz parte da situação narrada ou estava como observador? Explique.

- Qual o cenário em que a crônica é narrada? É um lugar curioso? Há descrições desse local?

- A forma como as personagens se cumprimentam no primeiro encontro é adequada à situação? Justifique.

- Através dos objetos encontrados no lixo das personagens, é possível identificar a condição social delas? Justifique sua resposta com exemplos retirados do texto. 
- O texto apresenta palavras desconhecidas? Destaque-as e pesquise os significados no dicionário.

- Qual o tipo de discurso predomina no texto: direto, indireto ou indireto livre? Cite um exemplo destacado do texto.

- Quais sinais de pontuação são utilizados nos textos construídos com discurso direto?

Para concluir a atividade, através de um bate-papo coletivo, as/os alunas/os farão a socialização das respostas dadas as questões, enquanto a/o professor/a observa se houve uma apreensão dos conhecimentos acerca da crônica, trabalhados nas etapas anteriores da sequência.

\section{$5^{\circ}$ encontro: Módulo III: A imagem diz que...}

Nesse encontro, as/os alunas/os irão levar para aula uma foto ou imagem de sua cidade ou bairro (solicitada anteriormente pela/o professor/a) que tenha relação com a temática abordada na SD. Pode ser uma foto antiga que elas/eles tenham em sua casa ou fotografia tirada recentemente por meio do celular ou tablet. A turma será instigada a comentar sobre a imagem, debatendo questões como:

- Que imagem é retratada na foto?

- Quando e onde foi produzida? Como é esse lugar?

- Que elementos são destaque na imagem?

- De quem é a responsabilidade do problema apresentado na imagem? 
- Que relação tem essa imagem com a temática abordada na crônica?

- O que é possível fazer para melhorar a qualidade de vida dos moradores desse lugar?

- De que forma você pode contribuir para a solução desse problema?

As/Os alunos deverão colar a imagem no caderno, responder às questões propostas e socializar suas respostas entre os colegas.

\section{$6^{\circ}$ encontro: Produção final}

A produção final é o momento em que a/o aluna/o põe em prática os conteúdos e as noções trabalhadas ao logo dos módulos. Para realizar essa etapa, a/o professor/a devolverá aos grupos a primeira produção, propondo-lhess olharem novamente para o texto que construíram, desta vez com um olhar crítico, e orientá-las/os na revisão e aprimoramento da escrita final, utilizando, para isto, os conhecimentos adquiridos nos módulos anteriores. Nesse momento, ocorrerá a reescrita do texto, cada grupo se voltará para sua produção, buscando aprimorar e refinar a nova versão.

Como todas as etapas da SD exigem um trabalho intenso por parte das/os estudantes, consideramos importante que os textos produzidos sejam apresentados à comunidade escolar. A divulgação poderá ser realizada através da organização de varais ou painéis expostos na área da escola. 


\section{Avaliação}

A avaliação das atividades desenvolvidas na SD será processual, incluindo a participação, o envolvimento e o empenho das/os alunos na realização de questões propostas.

Nesse sentido, ao utilizar a SD, é imprescindível às/aos professoras/es, segundo Laginestra e Pereira (2010, p. 2010, p. 14-15), avaliar as capacidades das/os alunas/os a partir de sua escrita inicial, observando o que já sabem e assinalando as lacunas e os erros. As autoras consideram igualmente importante estimular a escrita criativa das/os alunos, para que aprendam a refletir sobre seu texto, a reler, a revisar, a corrigir os erros e a melhorar seus textos, percebendo que a escrita é um processo que precisa ser constantemente aperfeiçoado.

Portanto, propomos uma avaliação como um processo dinâmico e sistemático que acompanha o desenvolvimento pedagógico do ato educativo de modo a permitir a constante formação das/os alunas/os.

\section{Considerações finais}

É desejável, como nos lembra Pinheiro (2001, p. 21), que o aluno tenha uma experiência de leitura prazerosa e significativa. Isso é possível quando o jovem leitor se sente representado de algum modo nas obras que lê, para poder atribuir sentidos à sua leitura. Corroborando nesse mesmo sentido, Cruz (2009, p. 146) defende a teoria de que o leitor, ao entrar em contato com o texto literário, depara-se com uma nova experiência que o aproxima de uma situação singular, a princípio, estranha a seu entendimento. É nesse instante que se dá início a um intercâmbio com o mundo da leitura escrita, em consonância com o universo dos significados múltiplos.

Nesse sentido, o gênero crônica, como objeto de ensino, constitui uma das estratégias, pela via do literário, da qual a/o professor/a pode fazer uso nas aulas de leitura, 
visto que "Ao escrever, os cronistas buscam emocionar e envolver seus leitores, convidando-os a refletir, de modo sutil, sobre situações do cotidiano, vistas por meio de olhares irônicos, sérios ou poéticos, mas sempre agudos e atentos.” (LAGINESTRA; PEREIRA, 2010 , p. 21). Desse modo, a proposta de atividade aqui apresentada visa a subsidiar o professor na promoção da formação de alunos leitores de textos literários no ambiente escolar e, quiçá, em sua rotina social e profissional.

De fato, no que tange à proposta de ensino, tendo como eixo a sequência didática, sua aplicação justifica-se por viabilizar o desenvolvimento das capacidades de expressão oral e escrita dos alunos, nas mais diversas situações de comunicação, tanto no ambiente escolar como fora dele. Por meio do uso da SD nas aulas, também é possível às/aos professoras/es articular a produção textual ao ensino de aspectos linguísticos do idioma, tais como ortografia, morfologia, pontuação e sintaxe, entre outros. Enfim, a SD pode permitir à/ao aluna/o melhorar seus conhecimentos acerca de um gênero textual, antes talvez considerado desconhecido em suas práticas de leitura.

É interessante, portanto, que o texto literário no espaço escolar seja um recurso que possibilite encontros, convergências e/ou divergências, heterogeneidades e experiências diversas com os contextos do leitor. Somente assim o ensino com e pela literatura no EF II será uma prática para o letramento e, como tal, imprescindível na formação cognitiva e sociocultural da/o aluna/o que se encontra na Educação Básica.

\title{
READING PRACTICES IN THE CLASSROOM: A DIDACTIC SEQUENCE FOR LIT- ERARY LITERACY
}

\begin{abstract}
The paper discusses questions related to reading in the classroom, emphasizing it as a fundamental process for the development of expression, communication and social interaction of learners. Understanding the reading practice in the school as an activity that demands planning and elaboration of objectives, we make arguments in favor of the use of the strategies to favor the reading and interpretative understanding, in contextualized situations. Therefore, we suggest a teaching proposal elaborated from the didactic sequence model delineated by Dolz, Noverraz and Schneuwly (2004). We used the chronicle "The garbage", by Luis Fernando Veríssimo, as literary object. To support this proposal, we support, among others, the studies of Oliveira (2010), Solé (1998), Cosson (2014) and Colomer and Camps (2002), which present pertinent contributions on reading practices
\end{abstract}


and reading comprehension in space school, as well as reflections on the formation of the reader of literary texts.

KEYWORDS: Reading strategies; Literary reading; Following teaching.

\section{REFERÊNCIAS}

ANTUNES, Irandé. Lingua, texto e ensino. São Paulo: Parábola Editorial, 2009.

BRASIL, Secretaria da Educação Fundamental. Parâmetros Curriculares Nacionais - terceiro e quarto ciclos do ensino fundamental: Língua Portuguesa. Brasília: Ministério da Educação e Cultura, 1998.

COSSON, Rildo. Letramento literário: teoria e prática. 1. ed. 1. Reimp. São Paulo: Contexto, 2014.

COLOMER, Tereza; CAMPS, Anna. Ensinar a ler, ensinar a compreender. Porto Alegre: Artmed, 2002.

DIONÍSIO, Maria de Lourdes. Literatura, leitura e escola. Uma hipótese de trabalho para a construção do leitor cosmopolita. In: PAIVA, Aparecida; MARTINS, Aracy; PAULINO, Graça; VERSIANI, Zélia (Orgs.). Leituras literárias: discursos transitivos. 2. ed. Belo Horizonte: Autêntica Editora, 2014.

DOLZ, Joaquim; NOVERRAZ, Michèle; SCHNEUWLY, Bernard. Sequências didáticas para o oral e a escrita: apresentação de um procedimento. In: Gêneros orais e escritos na escola. Tradução e organização: Roxane Rojo e Glaís Sales Cordeiro. Campinas, SP: Mercado de Letras, 2004. p. 149-185.

LAGINESTRA Maria Aparecida; PEREIRA Maria Imaculada. $A$ ocasião faz o escritor: caderno do professor: orientação para produção de textos. São Paulo: Cenpec, 2010. (Coleção da Olimpíada)

OLIVEIRA, Luciano Amaral. Coisas que todo professor de português precisa saber: teoria e prática. São Paulo: Parábola Editorial, 2010.

PINHEIRO, Hélder. Literatura no ensino médio: uma hipótese de trabalho. In: DIAS, Luiz Francisco (Org.). Texto, escrita e interpretação: ensino e pesquisa. João Pessoa: Editora Ideia, 2001.

RANGEL, Egon de Oliveira. Letramento literário e livro didático de língua portuguesa: "os amores difíceis". In: PAIVA, Aparecida; MARTINS, Aracy; PAULINO, Graça; VERSIANI, Zélia (Orgs.). Literatura e letramento: espaços, suportes e interfaces: o jogo do livro. 1. ed. 2. Reimp.. Belo Horizonte: Autêntica/CEALE/FaE/UFMG, 2007. 
. Literatura e livro didático no ensino médio: caminhos e ciladas na formação do leitor. In: PAIVA, Aparecida; MARTINS, Aracy; PAULINO, Graça; VERSIANI, Zélia (Orgs.). Leituras literárias: discursos transitivos. 2. ed. Belo Horizonte: Autêntica Editora, 2014.

REZENDE, Neide Luzia de. O ideal de formação pela literatura em conflito com as práticas de leitura contemporâneas. In: SANTINI, Juliana (Org.). Literatura, crítica e leitura. Uberlândia: EDUFU, 2011.

O ensino de leitura e a leitura literária. In: DALVI, Maria Amélia; REZENDE, Neide Luzia de; JOVER-FALEIROS, Rita (Orgs.). Leitura e literatura na escola. São Paulo: Parábola, 2013. p. 99-112.

SOLÉ, Isabel. Ler, leitura, compreensão: "Sempre falamos a mesma coisa?". In: TEBEROSKY, Ana et al. Compreensão de leitura: a língua como procedimento. Trad. Fátima Murad. Porto Alegre: Artmed, 2003.

ZILBERMAN, Regina; SILVA, Ezequiel Theodoro da (Orgs.). Literatura e pedagogia: ponto \& contraponto. 2. ed. São Paulo: Global, 2008.

Recebido em: 19/09/2017. Aprovado em: 14/11/2017. 